\title{
Expert Consensus on the Management of Brain Arteriovenous Malformations
}

\begin{abstract}
Brain arteriovenous malformations (bAVMs) are complex, heterogeneous, and uncommon intracranial lesions. They can be treated by one or a combination of the following treatment modalities, namely embolization, radiosurgery, or microsurgical resection. In Spetzler-Martin Grade 4 and 5 arteriovenous malformations (AVMs), conservative management may be the best option. A group of experts in the management of AVMs of different disciplines gathered in January 2019 in Hanoi to compile the "Expert Consensus on the Management of Brain Arteriovenous Malformations".
\end{abstract}

Keywords: Brain arteriovenous malformation, expert consensus, management

\section{Introduction}

Brain arteriovenous malformations (bAVMs) are complex, heterogeneous, uncommon lesions that can lead to significant neurological disability or death, most commonly from intracranial hemorrhage (ICH). ${ }^{[1,2]}$ In 2014, A Randomized Trial of Unruptured Brain Arteriovenous Malformations (ARUBA), comparing interventional therapy and medical management of unruptured bAVMs, concluded that the natural history of arteriovenous malformations (AVMs) on a rather short follow-up (33 months) is better than any form of treatment. ${ }^{[3]}$ This result has significantly altered the treatment decision for AVMs.

AVMs can also be incidental findings during investigation of unrelated symptoms. Population-based data suggest that the annual incidence of discovery of a symptomatic AVM is approximately $1 / 100,000$ population. ${ }^{[1,2,4-6]}$ Although the ARUBA study was a major contribution to the literature, it has been the object of many criticisms by the scientific community ${ }^{[7-10]}$ because of its discordances with the results of many published reports ${ }^{[11-13]}$ and the experience of the clinicians dealing with AVMs.

AVM is a dynamic disease. One grade does not fit all. Treatment may differ for symptomatic versus asymptomatic,

This is an open access journal, and articles are distributed under the terms of the Creative Commons Attribution-NonCommercial-ShareAlike 4.0 License, which allows others to remix, tweak, and build upon the work non-commercially, as long as appropriate credit is given and the new creations are licensed under the identical terms.

For reprints contact: reprints@medknow.com emergency, or elective. The management of bAVMs should integrate not only the imageology but also the complete history, examination, and general condition of the patient. Any form of treatment must target the complete obliteration of the malformation.

\section{Methodology}

This consensus statement has been made following comprehensive review of the current medical literature. The recommendations were then developed with consensus following face-to-face meeting by a group of subject-matter experts from around the world. The meeting was conducted in a question and answer format, and a final group discussion reached a general consensus.

Natural history of brain arteriovenous malformation

bAVMs are considered sporadic congenital developmental vascular lesions, but their pathogenesis is not well understood. Rare cases of familial bAVMs were reported, but it is unclear if these are coincidental or indicate true familial occurrence. ${ }^{[14]}$ However, genetic variation may influence bAVM development and clinical course. ${ }^{[15,16]}$

There is a higher prevalence of vascular malformations associated with hereditary hemorrhagic telangiectasia (HHT; Osler-Weber-Rendu syndrome). ${ }^{[17]}$ AVMs are associated with the EPHB4 mutation in patients with multifocal cavernous

How to cite this article: Kato Y, Dong VH, Chaddad F, Takizawa K, Izumo T, Fukuda $\mathrm{H}$, et al. Expert consensus on the management of brain arteriovenous malformations. Asian J Neurosurg 2019;14:1074-81.

\author{
Yoko Kato, \\ Van He Dong ${ }^{1}$, \\ Feres Chaddad ${ }^{2}$, \\ Katsumi Takizawa ${ }^{3}$, \\ Tsuyoshi Izumo ${ }^{4}$, \\ Hitoshi Fukuda ${ }^{5}$, \\ Takayuki Hara6, \\ Kenichiro Kikuta ${ }^{7}$, \\ Yasunobu Nakai ${ }^{8}$, \\ Toshiki Endo ${ }^{\text {, }}$ \\ Hiroki Kurita ${ }^{10}$, \\ Bin $X \mathbf{u}^{11}$, \\ Vladimír Beneš ${ }^{12}$, \\ Raftopoulos \\ Christian ${ }^{13}$, \\ Giacomo Pavesi ${ }^{14}$, \\ Mojgan Hodaie ${ }^{15}$, \\ Rajan Kumar \\ Sharma ${ }^{16}$, \\ Harshal Agarwal' ${ }^{17}$, \\ Krishna Mohan ${ }^{18}$, \\ Boon Seng Liew ${ }^{19}$ \\ Department of Neurosurgery, \\ Fujita Health University \\ Bantane Hospital, Nagoya, \\ Japan, ' Department of \\ Neurosurgery, VietDuc \\ University Hospital, Hoan Kiem, \\ Hanoi, Vietnam, ${ }^{2}$ Department \\ of Neurosurgery, Universidade \\ Federal de São Paulo, São \\ Paulo, Brazil, ${ }^{3}$ Department of \\ Neurosurgery, Japanese Red \\ Cross Asahikawa Hospital, \\ Asahikawa, ${ }^{4}$ Department \\ of Neurosurgery, Nagasaki \\ University Graduate School of \\ Biomedical Sciences, Sakamoto, \\ Nagasaki, ${ }^{5}$ Department of \\ Neurosurgery, Kochi University \\ Hospital, Nankoku, Kochi,
}

\section{Access this article online}

Website: www.asianjns.org

DOI: 10.4103/ajns.AJNS_234_19 Quick Response Code:

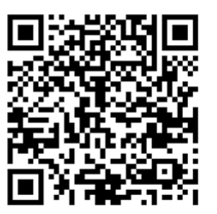


${ }^{6}$ Department of Neurosurgery, Toranomon Hospital, MinatoKu, Tokyo Japan, ${ }^{7}$ Department of Neurosurgery, University of Fukui, Fukui, ${ }^{8}$ Department of Neurosurgery, Tsukuba Medical Center Hospital, Tsukuba, Ibaraki, 'Department of Neurosurgery, Graduate School of Medicine, Tohoku University, 1-1 Seiryo Aoba, Sendai, ${ }^{10}$ Department of Cerebrovascular Surgery, International Medical Center, Saitama Medical University, Hidaka, Japan, ${ }^{11}$ Department of Neurosurgery, Huashan Hospital, Fudan University, Shanghai, China, ${ }^{12}$ Department of Neurosurgery and Neurooncology, First Faculty of Medicine, Charles University, Military University Hospital, Prague, Czech Republic, ${ }^{13}$ Department of Neurosurgery, Cliniques Universitaires SaintLuc Bruxelles, Brussels, Belgium, ${ }^{14}$ Department of Neurosurgery, Sant'Agostino Estense Hospital, Modena, Italy, ${ }^{15}$ Department of Surgery, University of Toronto, Toronto, Ontario, Canada, ${ }^{16}$ Department of Neurosurgery, Bir Hospital, National Academy of Medical Sciences, Kathmandu, Nepal, ${ }^{17}$ Apollo Hospitals, Chennai, Tamil Nadu, India, ${ }^{18}$ Department of Neurosurgery, SVIMS, Tirupathi, Andhra Pradesh, India, ${ }^{19}$ Department of Neurosurgery, Hospital Sungai Buloh, Selangor, Malaysia

\section{Address for correspondence:}

Prof. Yoko Kato,

Department of Neurosurgery, Fujita Health University Bantane Hospital, Nagoya, Japan.

E-mail: kyoko@fujita-hu.ac.jp

Dr. Boon Seng Liew,

Department of Neurosurgery, Hospital Sungai Buloh, Selangor, Malaysia.

E-mail: liew_bs@yahoo.com

malformations (CMs). The phenotype, CM-AVM2, mimics RASA1-related CM-AVM1 and also HHT. ${ }^{[18]}$ Patients with HHT may have cerebral or spinal cord involvement with telangiectasias, bAVMs, aneurysms, or CMs. The presence of more than one bAVM, otherwise uncommon, is highly predictive of HHT. ${ }^{[17]}$

The annual risk of a first-ever $\mathrm{ICH}$ from an unruptured bAVM is about $1 \%-3 \%{ }^{[19,20]}$ The hazard risk (HR) for bleeding in previously ruptured AVMs is 3.2 (95\% confidence interval: 2.1-4.3). ${ }^{[20]}$ The risk of bleeding when initial bleeding occurred during pregnancy was $6 \%$ at 1-year follow-up. ${ }^{[2]}$ Patients with ICH due to ruptured AVM have more favorable outcomes than patients with ICH from other causes. ${ }^{[2]}$

The 5-year risk of the first onset of seizure is about $8 \% .{ }^{[23]}$ The 5-year risk of developing epilepsy after a first seizure is about $58 \% \cdot{ }^{[19]}$ In contrast, patients who presented with $\mathrm{ICH}$ or focal neurologic deficits had a $23 \% 5$-year risk of seizures.

Smaller AVMs, ${ }^{[24]}$ the absence of AVM-associated arterial aneurysms, ${ }^{[24,25]}$ and supratentorial bAVMs ${ }^{[25]}$ were found to be predictors of a favorable outcome.

\section{Imaging modalities}

Digital subtraction angiography (DSA) allows a definitive diagnosis of a bAVM. The computed tomography (CT) and magnetic resonance imaging (MRI), including angiographic imaging (CT angiography [CTA] and magnetic resonance angiography [MRA]), can be reliably used to identify and analyze bAVMs. ${ }^{[19]}$ The clinical evaluation of bAVMs with MRA can be improved using intracranial high-resolution vessel wall MRI. ${ }^{[26]}$

The proximity of bAVMs to the critical white matter tracts and eloquent cortex can be evaluated using the functional MRI and diffusion tensor imaging-based tractography. This information can be used to improve patient selection and to choose the surgical approach. Hence, the chance of postoperative neurological deficits can be minimized. ${ }^{[19]}$

\section{Recommendations}

The committee made the following recommendations:

1. Holistic approach is advocated irrespective of the types of bAVMs

2. In surgical resection, a postoperative angiography is necessary to check for residual nidus. A check angiography can be facilitated by hybrid operative theater (OR) and performed before closure of craniotomy. This practice can helps to differentiate residual versus recurrent lesion. No follow-up angiography subsequently

3. In case of no access to a MRA, basic should be CTA and DSA.

\section{Grading systems}

Spetzler-Martin Grading (SMG) is the standard grading system for classification of AVMs. The SMG is useful for predicting the risk of surgical resection. ${ }^{[19]}$ The drawbacks of the SMG is the absence of mentioning the significance of different arterial feeders, patient status at the time of decision-making, and the compactness of the nidus. Other grading systems include Supplemented SMG System for bAVMs [Table 1]. It is used to strengthen its clinical utility in predicting surgical risk and selecting appropriate surgical candidates. ${ }^{[19,27]}$ Supplementary scoring system

\begin{tabular}{lcl}
\hline \multicolumn{2}{l}{ Table 1: Supplementary Spetzler-Martin grading system } \\
\hline SMG & Points & Supplementary grading \\
\hline Size $(\mathrm{cm})$ & & Age (years) \\
$<3$ & 1 & $<20$ \\
$3-6$ & 2 & $20-40$ \\
$>6$ & 3 & $>40$ \\
Venous drainage & & Bleeding \\
Superficial & 0 & Yes \\
Deep & 1 & No \\
Eloquence & & Compactness \\
No & 0 & Yes \\
Yes & 1 & No \\
Total & 5 & \\
SMG - Spetzler-Martin Grading &
\end{tabular}


added the following factors to augment the traditional SMG: patient age $(<20$ years $=1$ point; $20-40$ years $=2$ points; and $>40$ years $=3$ points $)$, bleeding or hemorrhagic presentation (yes $=0$ point and no $=1$ point), and nidus configuration (compact $=0$ point and diffuse $=1$ point). The Spetzler-Ponce class (SPC) simplification incorporates SMG 1 and 2 as SPC A, SMG 3 as SPC B, and SMG 4 and 5 as SPC $\mathrm{C}$. The 9-year complication-effectiveness analysis risk was $1.4 \%$ for SPC A, 22\%-24\% for SPC B, and $45 \%-63 \%$ for SPC C. ${ }^{[28]}$

There is an immediate need for a newer classification or extension of the present grading system. Although SPC and Lawson Grading have been developed, the benefit remains controversial. The time has come for precising the eloquent areas. Newer terms such as eloquent adjacent and far adjacent should be incorporated as, for example, an individual with motor cortex defect and visual field defect cannot carry the same points.

Subtypes of Grade II AVMs include Group 1 (S2V0E0), Group 2 (S1V0E1), and Group 3 (S1V1E0). In a cohort of Grade II AVMs, the subgroup analysis between Group 1 and Group 3 revealed more patients with worsened Modified Rankin Scale (mRS) who were observed in Group $3(P=0.039)$. This distinction was further confirmed in surgically treated patients $(P=0.049)$ but not in patients treated with radiosurgery $(P=0.863)$. The study concluded that Group 1 (S2V0E0) patients had the best functional outcome gain from treatment, whereas Group 3 (S1V1E0) patients fared less well, particularly with surgical treatment. ${ }^{[29]}$

Age is a factor to be considered in decision-making. The prevalence of elderly patients with AVMs was reported to comprise only $2 \%-6 \%$ of all AVMs. ${ }^{[30,31]}$ Around 5\%-18\% of AVM patients present over the age of 60 years. ${ }^{[32,33]}$ When there is no postoperative morbidity with the available techniques, the treatment of AVMs in the elderly is justified; recent reports have revisited the treatment of AVM in elderly patients and demonstrated that obliteration of the lesion leads to acceptable treatment outcomes from both surgery and radiosurgery series, thereby favoring a more aggressive approach to achieve lesion obliteration.

\section{Recommendations}

The committee made the following recommendations:

1. SMG is standard. None have experience with Lawton grades. There is a need of newer classification to incorporate feeders, patient status at the time of decision-making, and compactness of the nidus. SMG helps in information and communication of a given AVM. Devise grading is necessary to classify patients to select optimum treatment plan in case of multimodal approach

2. Eloquence of adjacent cortex should be precised. Eloquent adjacent and far adjacent are newer potential terms. A patient with a motor deficit versus visual field defect cannot carry the same points

3. Looking at feeders:

a. Superficial versus deep

b. Cortical, lenticulostriate, choroidal, and thalamoperforating arteries.

4. Age is a factor to be considered in decision-making.

Note: Only simple and easy scoring systems are accepted by the neurosurgical community. Thus, Spetzler-Martin (Ponce) was successful and will remain so.

\section{Treatments}

A hybrid OR is always a better option while operating AVM. An experienced neurosurgical team is a prerequisite, and the armamentarium should include high end operating microscope, ultrasonic Doppler, indocyanine green (ICG), dual-image videoangiography, and endoscope to look beyond the nidus and confirm. These will add to the completion of surgery. Immediate check angiography is needed to check for residual nidus. ICG can be used preferably before opening the dura to see the nidus, feeders, and draining veins and help open dura accordingly. Stereotactic neuronavigation has been used to permit smaller, more accurate, and more effective approaches to bAVM surgery. Intraoperative vascular imaging, including DSA, ICG videoangiography, and fluorescein videoangiography have been applied to bAVM surgery. ${ }^{[19]}$ Immediate check angiography is needed to check for residual nidus.

In a case of a ruptured AVM with life-threatening mass effect, surgical evacuation of an ICH is warranted. The main aim of the surgery is solely for the removal of hematoma and control of acute bleeding. However, for a small and superficial bAVMs, it can be removed during the same emergency surgery. Meanwhile, for a larger and deep bAVMs, the resection may be deferred for a period of 2-6 weeks. ${ }^{[19]}$ The deferment of definitive treatment allows reduction in brain swelling. Hence, a better delineation of the residual bAVM both angiographically and surgically can be achieved for a safe resection of the malformation.

Stereotactic radiosurgery (SRS) offers an acceptable risk to benefit profile for patients with unruptured bAVMs. ${ }^{[24]}$ SRS appears to be best suited for small-to-moderate-volume bAVMs that are generally $<12 \mathrm{~cm}^{3}$ in volume or $<3 \mathrm{~cm}$ in maximum diameter. ${ }^{[19]}$

SRS is also well suited for bAVMs located in deep or eloquent regions of the brain. ${ }^{[19]}$ In an unruptured AVM cohort treated with radiosurgery, $71 \%$ of AVMs were located in eloquent brain areas and the AVM obliteration was achieved in $65 \%$. The annual postradiosurgery hemorrhage rate was $1.4 \%$. Symptomatic and permanent radiation-induced changes occurred in $9 \%$ and $3 \%$, respectively. Overall, favorable outcome was achieved in $61 \%$. $^{[24]}$ 
Advances in SRS procedures have resulted in a lower risk of radiation-induced complications (RICs). ${ }^{[34]}$ SRS may also be performed after embolization to reduce nidal volumes and potentially to improve nidal obliteration rates. ${ }^{[19]}$

The obliteration rate of endovascular embolization alone does not exceed $60 \%$. In a study by Singfer et al., the standard occlusion rate was only $29.8 \%$ with endovascular embolization alone but a high overall occlusion rate of $73.7 \%$ in combination with SRS. However, the morbidity needs to be considered when a therapy is planned, even if it seems lower than in the ARUBA trial. ${ }^{[35]}$

\section{Recommendations}

The committee made the following recommendations:

1. Surgery is curative and definitive

2. Any form of treatment directed for AVMs should have complete obliteration of the nidus. Alternatively: Complete occlusion of AVM is the only acceptable target of any treatment

3. Counseling for other modalities. In the event of embolization or radiotherapy, patients should be adequately made aware of risks of rupture and complications in selecting nonsurgical management of AVMs

4. Recurrent and residual lesions have to be treated surgically.

\section{Presurgical embolization}

Presurgical embolization helps in reducing the size of the nidus and the risk of hemorrhage during surgery. Microsurgical resection may be performed after endovascular embolization to reduce bleeding risks during surgery and to facilitate complete and uncomplicated removal. ${ }^{[19]}$ The endovascular embolization also acts as adjunctive therapy for volume reduction before surgical resection. ${ }^{[36]}$ It is a temporary procedure and should be followed by surgery or radiosurgery.

Those arterial feeders that would be difficult to access in early stages of surgery should be eliminated by embolization. Hence, it helps in the reduction in flow or nidus volume that would permit safer surgical removal. Embolization is also used as a treatment of high-risk angiographic features, including feeding artery and intranidal aneurysms. ${ }^{[19]}$

Time frame between embolization and surgery is debatable with surgeons preferring 1 day. Hybrid OR allows to perform both procedures seamlessly. Onyx is the agent of choice, and deep feeders are targeted, whereas superficial feeders can be spared. This allows nidus to be identified at ease. Staged reduction of high-grade AVMs can be done by sequential transarterial embolization (TAE). Every TAE may increase the risk of hemorrhage. The disadvantage of presurgical embolization is that it usually makes the nidus hard and difficult to dissect.

\section{Recommendations}

The committee made the following recommendations regarding presurgical embolization:

1. Pros: It helps in reducing the size of the nidus and the risk of hemorrhage during surgery. It is a temporary procedure and should be followed by surgery. Time frame is not defined with surgeons preferring $24 \mathrm{~h}$. Hybrid OR helps in intraoperative decision-making. Onyx is the agent of choice. Deep feeders are targeted, whereas superficial feeders can be spared, which makes it easier to identify the nidus. Staged reduction of high-grade AVMs can be performed by sequential TAE

2. Cons: It makes nidus hard and difficult to dissect. Every TAE increases the risk of hemorrhage. Presurgical embolization of the superficial part alone of a large AVM makes access to the deeper part difficult.

\section{Surgical technique}

The sequential steps in surgical resection of a bAVMs are as follows: ${ }^{[19]}$

1. Adequate exposure to the bAVM and its arterial feeders and venous outflow by a craniotomy and duratomy

2. Its arterial feeders are isolated and divided

3. The nidus is dissected circumferentially from the adjacent brain parenchyma and surrounding neurovascular structures

4. The venous outflow is disconnected

5. Closure of the wound.

Microsurgical resection allows a high rate of complete nidus obliteration and immediately eliminates hemorrhage risk with a long-term durability when compared to other treatment options. Its main disadvantages are its invasiveness, length of recovery, and associated neurological risks. ${ }^{[19]}$

\section{Recommendations}

The committee made the following recommendations:

1. Surgery: To stick in the arachnoid plane or gliotic plane around lesion

2. ICG: Before opening dura to see the nidus, feeders, and draining veins and help open dura accordingly.

\section{Grade III and high-grade arteriovenous malformations}

Stapf et al. noted a significant difference between annual hemorrhagic risk in different patient subgroups, with the lowest group having an annual risk of $0.9 \% /$ year (superficial nidus, superficial draining vein) and the highest being $34.4 \%$ (deeply located nidus, deep venous drainage). ${ }^{[37]}$ Yang et al. compared long-term outcomes of patients with giant bAVMs (Grades III, IV, and V) treated conservatively with those subjected to interventions. They concluded that no significant difference in the risk of first subsequent hemorrhage was observed $(P=0.78)$ between groups. They also observed that despite comparable $\mathrm{mRS}$ scores at presentation, it was observed 
a trend toward better outcomes in patients undergoing conservative management $(P=0.06)$ compared with the intervention group at last follow-up. This study suggests that interventions for giant AVMs should be considered cautiously because hemorrhagic risk is similar regardless of management strategy and functional outcome is likely to be same or better in the conservatively managed population. ${ }^{[38]}$

Current conformal dose-planning techniques may improve the obliteration rate while maintaining a low risk of RICs even with the increment in the prescription dose for patients with medium- and large-volume AVMs. ${ }^{[34]}$ The reduction in the rate of adverse radiation effects in the treatment of a large AVMs can be achieved using staged-volume radiosurgery (SVRS) when compared with historical single-stage radiosurgery (SSRS) series. Obliteration and hemorrhage rates of large AVMs treated by SVRS are similar to historical SSRS. ${ }^{[39]}$

\section{Recommendations}

The committee made the following recommendations:

1. Grade 3 and 4 AVMs have to be treated with multimodal approach on a case-based selection

2. Grade 4 occipital or cerebellar AVMs have to be considered for surgery

3. Grade 5 AVMs have to be treated conservatively

4. Larger AVM patients may undergo staged TAEs. However, the risk of hemorrhage with each embolization procedure is around $7 \%$

5. Normal perfusion pressure breakthrough (NPPB) as a reason to recommend multistage nidus pressure reduction.

\section{Unruptured arteriovenous malformations}

Young patients with unruptured AVMs, surgery, or radiosurgery are recommended for unruptured SMG I and II AVMs. Radiosurgery is preferred for most patients with SMG III unruptured AVMs. For patients with unruptured SMG V AVMs and most patients with SMG IV AVMs, especially if the patient is older than 50 years, observation is preferred. Embolization which is used as an adjunct to surgery can also be used as a potentially curative therapeutic modality for very rare cases of very small AVMs with single feeding vessel. ${ }^{[40]}$ The risk of stroke in patients with small unruptured AVMs can be significantly reduced with SRS. ${ }^{[41]}$

Risks of hemorrhage in bAVMs include previous history of rupture (HR: 3.2), deep location and brain stem (HR: 2.4), and deep drainage vein (HR: 2.4). The risk of hemorrhage in nonruptured, superficially located with superficial draining vein is $<1 \%{ }^{[20]}$ Other factors which may be associated with the risk of hemorrhage in bAVMs are listed in Table 2.

The highly controversial ARUBA study marked an important turning point in the history of the management of unruptured bAVMs. ${ }^{[45,46]}$ However, despite the widely discussed limitations, many have interpreted the results as indicative that no unruptured AVM should be treated at all. ${ }^{[47]}$

There were opinions against ARUBA trial as it suggested that surgery was not the main part of the treatment and so its uniform applicability is questionable. Further trials should focus on the risk of rupture of AVM in a clinical setting and the risk of treatment and conservative management.

Limitations on A Randomized Trial of Unruptured Brain Arteriovenous Malformations

1. The study did not address the surgical outcome for patients with Grade 1 or 2 AVMs, who are the best candidates for surgery ${ }^{[20]}$

2. A significant proportion of suboptimal outcomes observed in the intervention arm of ARUBA were attributed by unconventional management strategy ${ }^{[44]}$

3. The studies excluded pediatric patients. The complication rates in the treatment arms were much higher than those reported in other studies ${ }^{[19]}$

\begin{tabular}{ll}
\hline \multicolumn{1}{c}{ Table 2: Factors associated with the risk of hemorrhage in brain arteriovenous malformations } \\
\hline Factors & Findings \\
\hline Size of AVMs & Larger HR: $0.877(21 \% \text { in small and } 18 \% \text { in large AVM })^{[42]}$ \\
Location & Deep location and brain stem; HR: $2.4^{[20]}$ \\
Draining vein & Deep draining vein; HR: $2.4^{[20]}$ \\
& Restricted venous drainage (e.g., single, narrow, or occlusion of one or more principal draining vein $)^{[20]}$ \\
Supra-/infratentorial & Infratentorial (OR: 3.6$)^{[43]}$ \\
Aneurysm & Berry aneurysm in feeder artery; HR: $1.8^{[20]}$ \\
Pregnancy & OR for hemorrhage is $7.91^{[21]}$ \\
Intervention & GKS ${ }^{[42]}$ \\
& There is a risk of hemorrhage during the latency period before obliteration SRS. During this latency \\
& period, the risk of hemorrhage is about $1 \%$ to $3 \%$ per year and does not appear to be appreciably \\
altered from the natural history of bAVMs & \\
& Embolization (in unruptured patients, embolization alone with or without curative intent may confer \\
& worse hemorrhagic control than conservative management without improved functional status)
\end{tabular}
AVMs - Arteriovenous malformations; HR - Hazard risk; OR - Operative theater; GKS - Gamma Knife surgery; SRS - Stereotactic radiosurgery; bAVMs - Brain AVMs 
4. The interventional cohort included three different interventions which could not be grouped together to make an accurate general conclusion between the two $\operatorname{arms}^{[40]}$

5. Relatively short follow-up (3 years) to make definitive conclusions for a disease ${ }^{[19,40,48]}$

6. The choice of outcome measures was not appropriate based on the different optimal outcomes of each treatment technique ${ }^{[40]}$

7. Disproportionate number of patients treated with surgery and embolization. ${ }^{[48]}$

Studies post-A Randomized Trial of Unruptured Brain Arteriovenous Malformations

1. One hundred and fifty-five ARUBA-eligible patients had microsurgical resection (71.6\% surgery only and $25.2 \%$ with preoperative embolization) produced less disabling deficits than ARUBA with similar morbidity and AVM obliteration as other cohort series ${ }^{[49]}$

2. In other studies among ARUBAeligible patients, especially those with lowgrade (SMG I and II) AVMs whom been treated either with microsurgery alone or radiosurgery, favourable results were obtained. ${ }^{[40,48]}$ The "New Assessment of Cerebral Arteriovenous Malformations yet Unruptured" (NASSAU study) showed that after the first 5year followup, relatively better outcome in the treated group than the conservative group. ${ }^{[50]}$

\section{Recommendations}

The committee made the following recommendations:

1. There is a need of formation of AVM board with a team of neurosurgeons who specialize in AVM surgery, embolization, and radiation therapy, utilizing multimodal assessment

2. Treatment modality has to be individualized. AVM is a dynamic disease (One size does not fit all). Treatment may differ for symptomatic versus asymptomatic, emergency, or elective

3. In favor of ARUBA trial, it halted the overzealousness of the surgeon in the management of AVMs akin to the international subarachnoid aneurysm trial

4. Against ARUBA, surgical treatment did not form the main part of treatment and compared heterogeneous treatment methods with each other. Uniform applicability is questionable

5. Further trials should focus on treatment versus no treatment, risk of rupture of an AVM in a given clinical setting, risk of rupture versus no treatment, and risk of treatment.

Note: The only conclusion of ARUBA is that AVMs Grade I and II should be treated surgically regardless of presentation.
Intranidal aneurysm or aneurysm in feeder

Endovascular embolization with Onyx was performed to eliminate high-risk features before surgical resection or SRS. Coil embolization was also performed as indicated for associated aneurysms. ${ }^{[36]}$

\section{Recommendations}

The committee made the following recommendations:

1. In case of feeder artery or intranidal aneurysm, the aneurysm has to be taken first.

Training and education and cost-effectiveness

Optimum care can be afforded by proper training of neurosurgeon in the management of AVM pertaining to preoperative evaluation, confidence in surgery, technical skills in embolization, and postoperative management in the intensive care unit and wards.

For developing countries, cost analysis is a must in the management of AVMs. Not all centers have or can afford to have preoperative embolization. Cost-effectiveness of treatment should be considered in planning the management without compromising on optimum treatment.

Counseling for other modalities has to be done, and the patient should be offered all types of treatment choices and combination therapy.

In choosing between embolization or radiosurgery, patents should be adequately made aware of risks of rupture and complications in selecting nonsurgical management of AVMs

\section{Recommendations}

The committee made the following recommendations:

1. Optimum care can be afforded by proper training of neurosurgeon in the management of AVM pertaining to preoperative evaluation, confidence in surgery, technical skills in embolization, and postoperative management in ICU and wards

2. For developing countries, cost analysis is a must in the management of AVMs. Not all centers have or can afford to have preoperative embolization. Cost-effectiveness of treatment should be considered in planning the management without compromising on optimum treatment.

Note: Attention to this book "Brain Arteriovenous Malformations: Pathogenesis, Epidemiology, Diagnosis, Treatment and Outcome" published in 2017 (Post ARUBA) ${ }^{[51]}$

Financial support and sponsorship

Nil.

\section{Conflicts of interest}

There are no conflicts of interest. 


\section{References}

1. Brown RD Jr., Wiebers DO, Torner JC, O'Fallon WM. Frequency of intracranial hemorrhage as a presenting symptom and subtype analysis: A population-based study of intracranial vascular malformations in Olmsted country, Minnesota. J Neurosurg 1996;85:29-32.

2. Ogilvy CS, Stieg PE, Awad I, Brown RD Jr., Kondziolka D, Rosenwasser R, et al. AHA scientific statement: Recommendations for the management of intracranial arteriovenous malformations: A statement for healthcare professionals from a special writing group of the stroke council, American stroke association. Stroke 2001;32:1458-71.

3. Mohr JP, Parides MK, Stapf C, Moquete E, Moy CS, Overbey JR, et al. Medical management with or without interventional therapy for unruptured brain arteriovenous malformations (ARUBA): A multicentre, non-blinded, randomised trial. Lancet 2014;383:614-21.

4. Berman MF, Sciacca RR, Pile-Spellman J, Stapf C, Connolly ES Jr., Mohr JP, et al. The epidemiology of brain arteriovenous malformations. Neurosurgery 2000;47:389-96.

5. Brown RD Jr., Wiebers DO, Forbes G, O'Fallon WM, Piepgras DG, Marsh WR, et al. The natural history of unruptured intracranial arteriovenous malformations. J Neurosurg 1988;68:352-7.

6. Stapf C, Mohr JP, Pile-Spellman J, Solomon RA, Sacco RL, Connolly ES Jr. Epidemiology and natural history of arteriovenous malformations. Neurosurg Focus 2001;11:e1.

7. Cenzato M, Delitala A, Delfini R, Pasqualin A, Maira G, Esposito $\mathrm{V}$, et al. Position statement from the Italian society of neurosurgery on the ARUBA study. J Neurosurg Sci 2016;60:126-30.

8. Hong CS, Peterson EC, Ding D, Sur S, Hasan D, Dumont AS, et al. Intervention for A randomized trial of unruptured brain arteriovenous malformations (ARUBA) - Eligible patients: An evidence-based review. Clin Neurol Neurosurg 2016;150:133-8.

9. Magro E, Gentric JC, Darsaut TE, Ziegler D, Bojanowski MW, Raymond J. Responses to ARUBA: A systematic review and critical analysis for the design of future arteriovenous malformation trials. J Neurosurg 2017;126:486-94.

10. Meling TR, Proust F, Gruber A, Niemela M, Regli L, Roche PH, et al. On apples, oranges, and ARUBA. Acta Neurochir (Wien) 2014;156:1775-9.

11. Bervini D, Morgan MK, Ritson EA, Heller G. Surgery for unruptured arteriovenous malformations of the brain is better than conservative management for selected cases: A prospective cohort study. J Neurosurg 2014;121:878-90.

12. Ding D, Starke RM, Kano H, Lee JY, Mathieu D, Pierce J, et al. Stereotactic radiosurgery for Spetzler-Martin grade III arteriovenous malformations: An international multicenter study. J Neurosurg 2017;126:859-71.

13. Javadpour M, Al-Mahfoudh R, Mitchell PS, Kirollos R. Outcome of microsurgical excision of unruptured brain arteriovenous malformations in ARUBA-eligible patients. $\mathrm{Br} \mathrm{J}$ Neurosurg 2016;30:619-22.

14. van Beijnum J, van der Worp HB, Schippers HM, van Nieuwenhuizen O, Kappelle LJ, Rinkel GJ, et al. Familial occurrence of brain arteriovenous malformations: A systematic review. J Neurol Neurosurg Psychiatry 2007;78:1213-7.

15. Hashimoto T, Lawton MT, Wen G, Yang GY, Chaly T Jr., Stewart CL, et al. Gene microarray analysis of human brain arteriovenous malformations. Neurosurgery 2004;54:410-23.

16. Pawlikowska L, Tran MN, Achrol AS, McCulloch CE,
Ha C, Lind DL, et al. Polymorphisms in genes involved in inflammatory and angiogenic pathways and the risk of hemorrhagic presentation of brain arteriovenous malformations. Stroke 2004;35:2294-300.

17. Bharatha A, Faughnan ME, Kim H, Pourmohamad T, Krings T, Bayrak-Toydemir $\mathrm{P}$, et al. Brain arteriovenous malformation multiplicity predicts the diagnosis of hereditary hemorrhagic telangiectasia: Quantitative assessment. Stroke 2012;43:72-8.

18. Amyere M, Revencu N, Helaers R, Pairet E, Baselga E, Cordisco M, et al. Germline loss-of-function mutations in EPHB4 cause a second form of capillary malformation-arteriovenous malformation (CM-AVM2) deregulating RAS-MAPK signaling. Circulation 2017;136:1037-48.

19. Derdeyn CP, Zipfel GJ, Albuquerque FC, Cooke DL, Feldmann E, Sheehan JP, et al. Management of brain arteriovenous malformations: A scientific statement for healthcare professionals from the American Heart Association/American Stroke Association. Stroke 2017;48:e200-e224.

20. Solomon RA, Connolly ES Jr., Arteriovenous malformations of the brain. N Engl J Med 2017;377:498.

21. Lv X, Liu P, Li Y. The clinical characteristics and treatment of cerebral AVM in pregnancy. Neuroradiol J 2015;28:234-7.

22. Murthy SB, Merkler AE, Omran SS, Gialdini G, Gusdon A, Hartley B, et al. Outcomes after intracerebral hemorrhage from arteriovenous malformations. Neurology 2017;88:1882-8.

23. Josephson CB, Leach JP, Duncan R, Roberts RC, Counsell CE, Al-Shahi Salman R, et al. Seizure risk from cavernous or arteriovenous malformations: Prospective population-based study. Neurology 2011;76:1548-54.

24. Ding D, Starke RM, Kano H, Lee JY, Mathieu D, Pierce J, et al. Radiosurgery for unruptured brain arteriovenous malformations: An international multicenter retrospective cohort study. Neurosurgery 2017;80:888-98.

25. Orning J, Amin-Hanjani S, Hamade Y, Du X, Hage ZA, Aletich $\mathrm{V}$, et al. Increased prevalence and rupture status of feeder vessel aneurysms in posterior fossa arteriovenous malformations. J Neurointerv Surg 2016;8:1021-4.

26. Matouk CC, Cord BJ, Yeung J, Malhotra A, Johnson MH, Minja FJ, et al. High-resolution vessel wall magnetic resonance imaging in intracranial aneurysms and brain arteriovenous malformations. Top Magn Reson Imaging 2016;25:49-55.

27. Behbahnai M, Esfahani D, McGuire LS. Journal club: Validation of the supplemented Spetzler-Martin grading system for brain arteriovenous malformations in a multicenter cohort of 1009 surgical patients. Neurosurgery 2016;78:755-7.

28. Morgan MK, Wiedmann M, Assaad NN, Heller GZ. Complication-effectiveness analysis for brain arteriovenous malformation surgery: A prospective cohort study. Neurosurgery 2016;79:47-57.

29. Hung AL, Yang W, Westbroek EM, Garzon-Muvdi T, Caplan JM, Braileanu $\mathrm{M}$, et al. Differences in functional outcome across subtypes with Spetzler-Martin grade II arteriovenous malformations. Neurosurgery 2017;81:441-9.

30. Al-Shahi R, Fang JS, Lewis SC, Warlow CP. Prevalence of adults with brain arteriovenous malformations: A community based study in Scotland using capture-recapture analysis. J Neurol Neurosurg Psychiatry 2002;73:547-51.

31. Luo J, Lv X, Jiang C, Wu Z. Brain AVM characteristics and age. Eur J Radiol 2012;81:780-3.

32. Tong $\mathrm{X}, \mathrm{Wu} \mathrm{J}$, Lin $\mathrm{F}$, Cao Y, Zhao Y, Ning B, et al. Brain arteriovenous malformations in elderly patients: Clinical features and treatment outcome. Acta Neurochir (Wien) 2015; 157:1645-53. 
33. Ding D, Xu Z, Yen CP, Starke RM, Sheehan JP. Radiosurgery for cerebral arteriovenous malformations in elderly patients: Effect of advanced age on outcomes after intervention. World Neurosurg 2015;84:795-804.

34. Pollock BE, Link MJ, Stafford SL, Garces YI, Foote RL. Stereotactic radiosurgery for arteriovenous malformations: The effect of treatment period on patient outcomes. Neurosurgery 2016;78:499-509.

35. Singfer U, Hemelsoet D, Vanlangenhove $P$, Martens $F$, Verbeke L, Van Roost D, et al. Unruptured brain arteriovenous malformations: Primary ONYX embolization in ARUBA (A randomized trial of unruptured brain arteriovenous malformations)-eligible patients. Stroke 2017;48:3393-6.

36. Nerva JD, Kim LJ, Barber J, Rockhill JK, Hallam DK, Ghodke BV, et al. Outcomes of multimodality therapy in pediatric patients with ruptured and unruptured brain arteriovenous malformations. Neurosurgery 2016;78:695-707.

37. Stapf C, Mast H, Sciacca RR, Choi JH, Khaw AV, Connolly ES, et al. Predictors of hemorrhage in patients with untreated brain arteriovenous malformation. Neurology 2006;66:1350-5.

38. Yang W, Wei Z, Wang JY, Hung AL, Caplan JM, Braileanu M, et al. Long-term outcomes of patients with giant intracranial arteriovenous malformations. Neurosurgery 2016;79:116-24.

39. Nagy G, Grainger A, Hodgson TJ, Rowe JG, Coley SC, Kemeny AA, et al. Staged-volume radiosurgery of large arteriovenous malformations improves outcome by reducing the rate of adverse radiation effects. Neurosurgery 2017;80:180-92.

40. Sorenson T, Lanzino G. Current management of unruptured brain arteriovenous malformations. Contemp Neurosurg 2017;39:1-5.

41. Hanakita S, Shin M, Koga T, Igaki H, Saito N. Risk reduction of cerebral stroke after stereotactic radiosurgery for small unruptured brain arteriovenous malformations. Stroke 2016;47:1247-52.

42. Yen CP, Sheehan JP, Schwyzer L, Schlesinger D. Hemorrhage risk of cerebral arteriovenous malformations before and during the latency period after GAMMA knife radiosurgery. Stroke 2011;42:1691-6.
43. Khaw AV, Mohr JP, Sciacca RR, Schumacher HC, Hartmann A, Pile-Spellman J, et al. Association of infratentorial brain arteriovenous malformations with hemorrhage at initial presentation. Stroke 2004;35:660-3.

44. Yang W, Porras JL, Xu R, Braileanu M, Khalid S, Hung AL, et al. Comparison of hemorrhagic risk in intracranial arteriovenous malformations between conservative management and embolization as the single treatment modality. Neurosurgery 2018;82:481-90.

45. Mohr JP, Overbey JR, von Kummer R, Stefani MA, Libman R, Stapf C, et al. Functional impairments for outcomes in a randomized trial of unruptured brain AVMs. Neurology 2017;89:1499-506.

46. Cockroft KM, Chang KE, Lehman EB, Harbaugh RE. AVM management equipoise survey: Physician opinions regarding the management of brain arteriovenous malformations. J Neurointerv Surg 2014;6:748-53.

47. Byar DP. Problems with using observational databases to compare treatments. Stat Med 1991;10:663-6.

48. Lang M, Moore NZ, Rasmussen PA, Bain MD. Treatment outcomes of A randomized trial of unruptured brain arteriovenous malformation-eligible unruptured brain arteriovenous malformation patients. Neurosurgery 2018;83:548-55.

49. Wong J, Slomovic A, Ibrahim G, Radovanovic I, Tymianski M. Microsurgery for ARUBA trial (A randomized trial of unruptured brain arteriovenous malformation)-eligible unruptured brain arteriovenous malformations. Stroke 2017;48:136-44.

50. Karlsson B, Jokura H, Yang HC, Yamamoto M, Martinez R, Kawagishi J, et al. The NASSAU (New ASSessment of cerebral arteriovenous malformations yet unruptured) analysis: Are the results from the ARUBA trial also applicable to unruptured arteriovenous malformations deemed suitable for gamma knife surgery? Neurosurgery 2019;85:E118-24.

51. Beneš V, Bradáč $O$. Brain Arteriovenous Malformations: Pathogenesis, Epidemiology, Diagnosis, Treatment and Outcome. Cham, Switzerland: Springer International Publishing; 2017. 